\title{
Kajian Desain Rumah Sakit Mobil
}

\author{
Ilya Fadjar Maharika, ${ }^{1}$ Risdiyono, ${ }^{2}$ Medilla Kusriyanto, ${ }^{3}$ Ari Sujarwo, ${ }^{4}$ Fitri \\ Nugraheni, ${ }^{5}$ Awaluddin Nurmianto, ${ }^{6}$ Retno Danarti, ${ }^{7}$ Suswardana, ${ }^{8}$ Raka Affa Arasya \\ Maharika, ${ }^{9}$ Titania Nur Fadillah ${ }^{10}$ \\ 1 Jurusan Arsitektur, Universitas Islam Indonesia, Yogyakarta \\ 2 Jurusan Teknik Mesin, Universitas Islam Indonesia, Yogyakarta \\ ${ }^{3}$ Jurusan Teknik Elektro, Universitas Islam Indonesia, Yogyakarta \\ ${ }^{4}$ Jurusan Informatika, Universitas Islam Indonesia, Yogyakarta \\ 5 Jurusan Teknik Sipil, Universitas Islam Indonesia, Yogyakarta \\ 6 Jurusan Teknik Lingkungan, Universitas Islam Indonesia, Yogyakarta \\ ${ }^{7}$ Departemen Dermatologi dan Venereologi, Universitas Gadjah Mada, Yogyakarta \\ ${ }^{8}$ Pusat Kesehatan, Markas Besar Tentara Nasional Indonesia \\ ${ }^{9}$ Sustainable Landscape and Architecture, Politecnico di Milano, Italia \\ ${ }^{10}$ Architectural Engineering, Politecnico di Milano, Italia \\ ${ }^{I}$ Email korespondensi: maharika@uii.ac.id
}

\begin{abstract}
INFORMASI ARTIKEL
Abstract: Disasters and pandemics require an agile health system response. The geographical character of Indonesia also demands agility on the one hand and system integration on the other which has not been fully responded to by existing systems that rely on stationary infrastructure. Currently, in the literature and global practice, a mobile health care system has become a trend but has not yet become part of the discourse in Indonesia. This research aims to initiate a modular hospital design to fill this systemic gap. This preliminary research was conducted using a narrative literature review method to identify critical design criteria as part of the design research methodology. This article recommends six criteria substantial for architectural design ideas and policy development for the mobile modular hospital.
\end{abstract}

Keywords: Modular Hospital, Mobile Hospital, COVID-19, Design Criteria

\begin{abstract}
Abstrak: Bencana dan pandemi memerlukan respon sistem kesehatan yang gesit. Karakter geografis Indonesia juga menuntut kelincahan di satu sisi dan integrasi sistem di sisi lain yang belum sepenuhnya direspons oleh sistem eksisting yang mengandalkan infrastruktur stasioner. Saat ini, dalam literatur dan praktik global, mobile health care system telah menjadi trend namun belum menjadi bagian dari wacana di Indonesia. Penelitian ini bertujuan untuk memulai desain rumah sakit modular untuk mengisi kesenjangan sistemik ini. Penelitian pendahuluan ini dilakukan dengan menggunakan metode tinjauan pustaka naratif untuk mengidentifikasi kriteria desain kritis sebagai bagian dari metodologi penelitian desain. Artikel ini merekomendasikan enam kriteria penting untuk ide desain arsitektur dan pengembangan kebijakan untuk rumah sakit mobile modular.
\end{abstract}

Kata kunci: Rumah Sakit Modular, Rumah Sakit Bergerak, COVID-19, Kriteria Desain

Article history:

Received ; 2021-06-18

Revised ; 2021-08-18

Accepted; 2021-09-18

\section{PENDAHULUAN}

Selain muncul tak terduga, bencana dapat berkembang menjadi skenario terburuk. Salah satu contoh adalah bencana wabah COVID-19 yang datang tiba-tiba dan muncul kekhawatiran pandemi ini dapat terus berkembang mencapai puncak, atau dapat berkembang kembali di kemudian hari dan menjadi berulang. Respons Indonesia pun masih terkendala dan direkomendasikan salah satunya adalah memperbaiki infrastruktur kesehatan serta melibatkan komunitas dalam memperkuat tanggap darurat dan kesiapsiagaan (Djalante, dkk. 2020). Indonesia yang rentan bencana dan dengan kondisi geografi yang beragam juga berpotensi menciptakan tekanan yang mendadak pada sistem pelayanan kesehatan di lokasi yang sulit diprediksi (gempa bumi, tsunami, banjir) dan dianggap masih banyak persoalan dalam 
responsnya (Widayatun \& Fatoni, 2013).

Sistem pelayanan kesehatan Indonesia saat ini mengandalkan pada sistem jejaring fasilitas kesehatan yang statis. Hal ini tampak pada Undang-Undang No 4 tahun 2009 Tentang Rumah Sakit yang menyandarkan mekanisme pendirian rumah sakit pada lokasi yang sesuai dengan tata ruang dan tidak menyinggung sistem yang mengandalkan mobilitas. Pada praktiknya, memang terdapat fasilitas yang bersifat mobil (mudah bergerak dan dipindahkan mobile dalam bahasa Inggris) seperti rumah sakit lapangan dan kapal Tentara Nasional Indonesia (TNI) namun dalam jumlah yang sedikit dan dalam kapasitas serta jangkauan yang terbatas. Dalam merespons COVID-19 misalnya rumah sakit lapangan TNI menjadi salah satu andalan dalam rangka memastikan kapasitas layanan dalam link berikut ini (https://nusantara.rmol.id/read/2021/02/09/474280/tangani-covid-19-ksad-perintahkantambah-kapasitas-rs-lapangan).

Namun demikian, dalam perundangan di atas, hal ini di luar sistem tata kelola sipil. Rumah Sakit Khusus Infeksi (RSKI) Pulau Galang pun walau menggunakan kontainer namun didesain dan dipraktikkan sebagai rumah sakit statis dan dikritik sebagai sebuah kesalahan respons kedaruratan karena aksesibilitas yang rendah (https://www.pikiranrakyat.com/nasional/pr-011521435/para-ahli-nilai-pemerintah-salah-kaprah-bangun-rskicovid-19-di-pulau-galang). Dengan demikian, sistem alternatif yaitu sistem yang mobil, modular, responsif, dinamis, dan dapat leluasa bergerak tersebut perlu dieksplorasi di level desain sistem maupun kebijakan sesuai kebutuhan lokalitas bencana dan karakteristik geografis Indonesia.

Di level global, solusi inovatif rumah sakit mobil (mobile hospital) tidak terlalu asing di tahap konsep maupun implementasi. Khanna \& Narula telah mencoba memetakan beragam fasilitas unit mobil ini dan menyimpulkan bahwa pembahasan tentang aspek ini masih menunjukkan lobang kesenjangan, sementara pada praktiknya telah berkembang untuk menjangkau pasien dan area yang sebelumnya tidak terjangkau (reach the unreachable) (Khanna \& Narula, 2016). Dalam praktik desain, Harrouk telah mengidentifikasi beragam konsep desain baik yang telah diimplementasikan maupun baru dalam tahap konsep (Harrouk, 2020) atau fasilitas yang telah dikembangkan menjadi komersial (https://hospitainer.com/). Di Indonesia, solusi ini telah diinisiasi di level komersial (https://superkontainer.com/jual-klinikcontainer/). Artinya, dari sisi teknologi hal ini dapat dilakukan oleh Indonesia namun di sisi kebijakan maupun sistem, produk ini belum menjadi sistem yang terintegrasi. Peralatan yang dimiliki TNI pun dalam konteks ini masih belum cukup memadai dan belum sepenuhnya plugin (mudah pasang) dan deployability (keterterapan) yang rendah terkait dengan moda transportasi misalnya pesawat terbang khususnya Hercules C-130 dan kapal rumah sakit TNI AL. Dengan demikian dari sisi teknis maupun implementasinya peluang pengembangan masih sangat terbuka lebar untuk inovasi baru.

Artikel ini bertujuan untuk melaporkan perkembangan konsep desain rumah sakit mobil (selanjutnya disebut RSM) yang merespons bencana dan pandemi. RSM merupakan jawaban hipotesis untuk pertanyaan bagaimana desain rumah sakit yang dapat merespons secara inovatif dan dinamis perkembangan ketidakterdugaan bencana, temasuk di dalamnya bencana wabah COVID-19. Dilaporkan pula kriteria keberhasilan desain RSM yang dapat dikembangkan menjadi bagian kebijakan layanan kesehatan. Temuan yang dilaporkan dalam artikel ini relevan untuk merespons tingkat kegawatdaruratan, intensitas, karakter, dan lokasi bencana yang cenderung meningkat. Demikian pula karakteristik geografis Indonesia yang berpulaupulau dengan aksesibilitas yang masih rendah memerlukan sistem layanan kesehatan dengan inovasi baru yang kontekstual. Inovasi RSM di dunia saat ini sedang berkembang menjadi penting dieksplorasi dan dikontekstualisasi dan sekaligus memberi respons balik berupa pengembangan keilmuan pada praktik desain fasilitas ini. 


\section{METODE PENELITIAN}

Artikel ini merupakan bagian dari penelitian yang mengkombinasikan proses desain (design process) dan penelitian terhadap desain yang mengikuti metodologi riset desain (design research methodology - DRM) yang dikembangkan oleh Blessing dan Chakrabarti (2009). DRM terdiri dari empat tahapan utama. (1) Pendefinisian desain (Design Clarification - DC) dilakukan untuk memperdalam dan mempertajam problem desain, membangun dugaan awal dan menetapkan kriteria awal. (2) Kajian deskriptif pertama (Descriptive Study 1 - DS1) ditujukan untuk memahami desain dari sudut pandang pengguna berbasis kriteria keberhasilan tertentu. (3) Kajian preskriptif (Prescriptive Study - PS) ditujukan untuk mengembangkan informasi pendukung (design support) bagi proses perancangan yang disusun berupa knowledge management dan design guideline. (4) Kajian deskriptif kedua (Descriptive Study 2 - DS2) ditujukan untuk melakukan evaluasi terhadap temuan yang telah diformulasikan pada tahap-tahap sebelumnya.

Artikel ini dimaksudkan sebagai laporan riset pendahuluan dan oleh karenanya melaporkan dua tahap saja dari DRM. Tahap pertama adalah pendefinisian desain. Dalam rangka memperdalam dan mempertajam problem penelitian, membangun dugaan awal dan menetapkan kriteria awal, pada tahap ini dilakukan studi literatur naratif (narrative literature review) yang melibatkan preseden desain dan kajian konteks rumah sakit di era pandemi. Menganut pemikiran Ferrari, narrative literature review ini merupakan metode yang tidak dapat ditinggalkan untuk menelusuri perkembangan pengetahuan, prinsip, ataupun konsep (Ferrari, 2015). Dengan penelusuran ini diiindikasikan kriteria umum dalam masalah desain RSM. Rujukan yang dieksplorasi sebagian terbesar adalah portal majalah arsitektur ArchDaily (https://www.archdaily.com) dan Dezeen (https://www.dezeen.com). Tahap kedua adalah kajian deskriptif yang ditujukan untuk memahami desain dari sudut pandang penggunaan. Artikel ini melaporan kriteria keberhasilan rancangan (success factor criteria) yang merupakan refleksi dari focus group discussion antara perancang (arsitek), insinyur, dan tenaga medis dikaitkan dengan kontekstualisasinya di Indonesia. Tahap-tahap DRM selanjutnya akan dilaporkan pada kesempatan yang lain.

\section{HASIL DAN PEMBAHASAN}

Telaah literatur dari sisi sejarah menunjukkan bahwa ide pengembangan rumah sakit mobil sebenarnya tidak baru terutama di militer. Penelusuran artikel di level sistem desain rumah sakit menunjukkan konsep mobilitas yang telah melintasi kurun waktu yang panjang. Dolev (2020) merinci sejarah rumah sakit lapangan yang mengungkapkan tradisi sejak jaman Romawi di dalam konteks peradaban Barat. Runutan ini diawali pada pengenalan konsep hospitalization yang diartikan sebagai penatakelolaan yang terorganisir untuk perawatan pasien sakit dan luka. Di mata tentara Romawi, perawatan yang terluka dianggap kebutuhan militer, tidak hanya karena memungkinkan peluang yang lebih baik untuk mengatasi masalah medis tetapi terutama sebagai solusi demoralisasi pasukan (Dolev, 2020). Artikel Jan (1996) merunut sejarah seorang perawat perempuan muslim yang berperan dalam perang Uhud pada tahun 625 Masehi bernama Rufaida Al-Asalmiya. Karena keahliannya dalam merawat, Rufaida diperintahkan oleh Rasulullah Muhammad untuk merawat prajurit yang terluka di dalam tenda yang didirikan di medan perang. Bagi kalangan muslim, beliau dianggap sebagai perintis keperawatan dan pendidikan perawat di dunia Islam dan meletakkan dasar keperawatan modern.

Konsep perawatan dalam tenda juga menunjukkan mulai dikenalnya rumah sakit lapangan yang bergerak mengikuti keberadaan korban yang berada di medan perang (Jan, 1996). Di Eropa, konsep ini dikembangkan oleh Baron Dominique Jean Larrey ketika perang Napoleon. Larrey dianggap oleh banyak orang sebagai bapak kedokteran perang yang meletakkan dasar evakuasi teknis dengan kereta yang disebut dengan istilah ambulance volante 
dan difungsikan sebagaimana ambulan saat ini. Dia juga salah satu dokter militer pertama yang membuat konsep rumah sakit bedah dengan membawa dukungan medis ke garis depan. Konsep ini diterjemahkan menjadi unit mobil dari Perang Dunia I (King \& Jatoi, 2005). Ensiklopedia Britannica merekam pengembangan prinsip ambulan ini dan penggunaan rumah sakit bedah tentara bergerak (mobile army surgical hospital - MASH) yang digunakan oleh pasukan Amerika Serikat selama Perang Korea pada 1950-an dan masih dioperasikan selama Perang Teluk Persia (1990-1991). Unit MASH memiliki 60 tempat tidur, membutuhkan 50 truk besar untuk dipindahkan, dan membutuhkan waktu 24 jam untuk penyiapan (https://www.britannica.com/science/mobile-army-surgical-hospital).

Dari sisi perkembangan konsepnya, laporan ilmiah penggunaan rumah sakit bergerak didapat seawal 1973 oleh Tahiliani dkk. (1973). Sayangnya tidak ada keterangan lebih detail dari artikel ini. Di level sistemik, Bakowski (2016) telah mendefinisikan perbedaan dua sistem dalam pengelolaan rumah sakit yaitu rumah sakit yang statits atau permanen (stationer) atau dan bergerak atau keliling (mobile). Rumah sakit permanen berperan sistemik dengan terminologi payung treatment (perawatan). Aktivitas promosi dan preventif termasuk dalam terminologi ini. RSM sering dikaitkan emergency (kedaruratan). Dalam terminologi ini masuk pula kondisi akut atau situasi krisis. Dalam konsep kedaruratan ini maka apapun bentuk organisasinya, RSM ini didasari pada serangkaian tindakan medis dalam rangka penyelamatan jiwa secara cepat. Jangkauan layanan ini terdiri dari prosedur medis yang terkait dengan cedera atau trauma mendadak. Dengan demikian gagasan rumah sakit mobil mengarah pada gagasan rumah sakit militer atau rumah sakit yang merespons bencana tidaklah keliru, baik bencana yang alami maupun yang disebabkan oleh faktor manusia. Mengikuti cara berpikir ini, fungsi rumah sakit bergerak atau keliling dapat dibatasi dan dibandingkan dengan area operasi gawat darurat (ED, emergency department). Dalam konsep ini, perawatan rawat inap menjadi di luar layanan utama bagi fasilitas ini. Namun demikian, dalam konteks sebagai fasilitas "terapeutik" RSM adalah fasilitas yang sepenuhnya menggantikan fungsi rumah sakit stasioner (Bakowski, 2016).

\section{Dasar konseptual rumah sakit mobil}

Dilihat dari sisi konsep arsitekturalnya, Chen dkk. (2020) melaporkan studinya yang didasarkan pada media transportasi, rumah sakit mobil dapat dikategorikan menjadi 3 jenis: (a) terestrial, (b) terapung, dan (c) terbang. Rumah sakit mobil terestrial adalah jenis yang paling umum, seperti rumah sakit tenda, rumah sakit dengan kendaraan, rumah sakit persinggahan, dan sebagainya. RSM terestrial bersifat modular. Jumlah unit, organisasi spasial, dan pilihan klinis dapat diubah sesuai kebutuhan. Dari sudut pandang struktur tata ruang, rumah sakit ini dapat segera menanggapi panggilan bencana dan segera berangkat ke zona bencana ketika situasinya memburuk. Syarat penting yang harus dipenuhi adalah medan yang rata dan secara fisik dapat dicapai dengan moda transportasi. Salah satu bentuk rumah sakit terestrial adalah memakai tenda yang memungkinkan medan yang lebih fleksibel namun memiliki kekurangan karena pemasangan dan pembongkaran yang memerlukan waktu lama. Rumah sakit terapung adalah fasilitas medis mandiri di laut. Konsep ini dipakai oleh militer maupun nonmiliter.

Saat ini banyak rumah sakit terapung yang beroperasi di seluruh dunia. Namun demikian, fasilitas seperti ini hanya dapat mencapai tujuan yang berada di dekat air, membutuhkan ruang manuver untuk berlabuh, dan harus tersedia akses bagi kapal untuk mengangkut pasien dan staf. Rumah sakit terbang telah diadopsi oleh banyak angkatan udara dunia, organisasi nirlaba, dan pemerintah. Rumah sakit terbang dapat menyediakan layanan rumah sakit bedah dan perawatan medis akut dalam situasi bencana, atau bantuan kemanusiaan. Selain itu, evakuasi aeromedis memberikan transportasi cepat bagi orang yang terluka di lokasi bencana ke rumah sakit. Namun demikian keterbatasan berupa medan untuk pendaratan dan kapasitas menjadi kendala pengembangan konsep ini secara luas (Chen dkk., 2020). 
Bakowski mengusulkan adanya kriteria untuk mengevaluasi solusi-solusi RSM ini yaitu (1) berdasar kriteria konstruksi dan logistik (construction and logistic criteria), dan (2) kriteria fungsional dan teknologis (functional and technological criteria). Kriteria pertama melibatkan solusi teknis, yang terkait tidak hanya dengan masalah konstruksi unit rumah sakit mobil, tetapi juga untuk arsitektur yang mobil. Masalah-masalah ini dapat dibawa ke dua terminologi: (a) modularitas yaitu kemampuan untuk mengemas fungsi ke dalam suatu wadah, dan (b) mobilitas yang dipahami sebagai kemudahan konstruksi untuk diangkut dari satu ke tempat lain. Modularitas harus menyediakan konstruksi struktur yang mungkin paling banyak dan beragam dari berbagai keperluan. Mobilitas adalah untuk memastikan solusi yang memungkinkan modul dimuat dan diangkut dengan cara pengiriman standar. Dengan cara ini, modul konstruksi arsitektur bergerak mendekati konstruksi dan ukuran wadah komoditas tipikal, diangkut dengan truk atau kapal, atau bahkan udara (Bakowski, 2016).

Perkembangan terbaru konsep mobilitas berkembang dalam konteks rumah sakit cerdas (smart hospital). Mobil di sini bukan dimaknai secara fisik melainkan kemampuan mobilisasi beragam layanan karena berbasis digital. Contoh eksplorasi mobile hospitalisation ini dilaporkan oleh Khalifa dkk. (2013). Mereka menunjukkan bahwa kemampuan mobilitas yang ditunjukkan oleh telepon pintar dan tablet agar dapat menjadi alat bantu untuk mengakses rekam medis dapat membantu sistem kesehatan dalam membentuk rumah sakit cerdas. Sistem pintar ini berbasis komputasi awan yang sangat bermanfaat dalam penyimpanan informasi rekam medis. Selain dapat memberi kapasitas penyimpanan tidak terbatas dan tidak perlu ruang yang besar untuk menyimpan, akses pun dapat hampir seketika karena tanpa mobilitas fisik yang membutuhkan waktu (Khalifa dkk. 2013). Dikonfirmasi pula bahwa kombinasi antara rumah sakit dan layanan mobil terbukti lebih efektif dalam melayani variasi kondisi pasien (Hugo dkk., 2002). Dari runutan sejarah di atas, perkembangan konseptual rumah sakit ini dapat digambarkan sebagaimana Gambar 1.

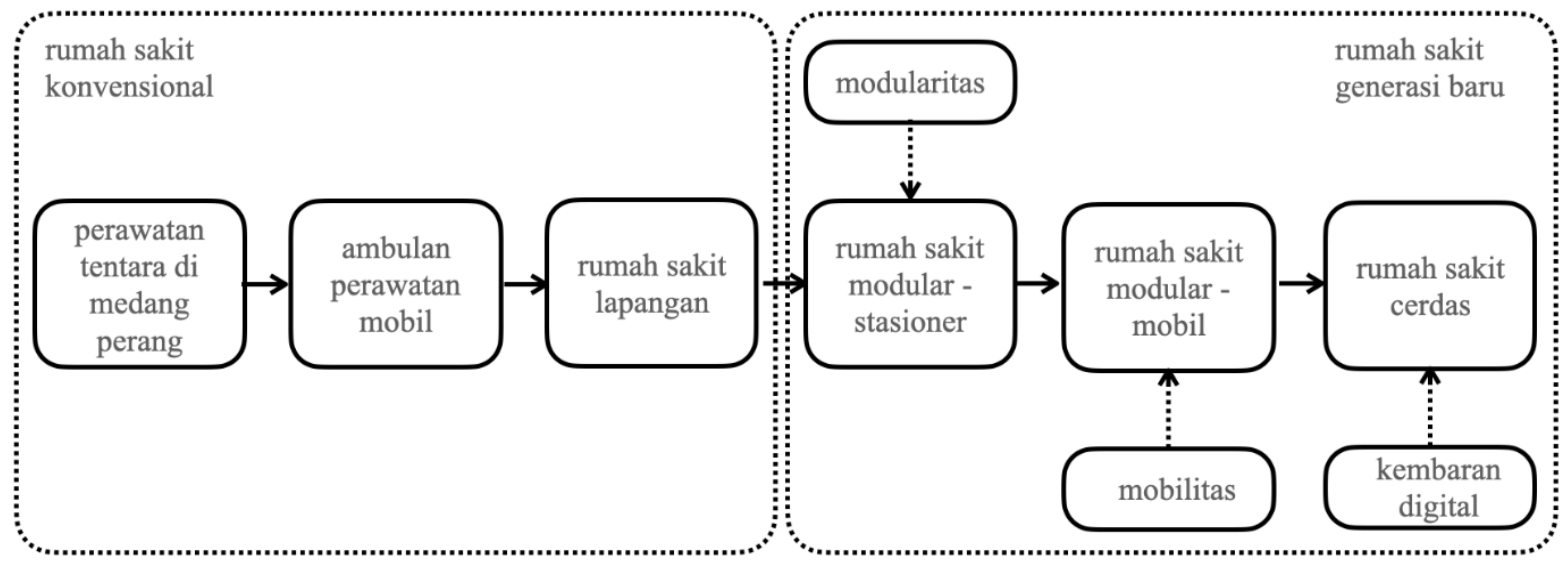

Gambar 1. Perjalanan konsep rumah sakit mobil

(sumber: analisis)

Perjalanan konsep arsitektural ini menunjukkan bahwa sistem berkembang dari pendekatan konvensional berbasis spasial berupa kedekatan lokasi layanan kesehatan ke medan tempur, atau mobilitas fisik melalui ambulan dan rumah sakit lapangan. Kehadiran teknologi konstruksi modular dan moda mobilitas yang lebih bervariasi memberi peluang hadirnya rumah sakit generasi baru. Perkembangan digital mendorong sistem baru berupa mobilitas nonfisik berupa data dengan infrastruktur komputasi awan (cloud computing). Namun demikian, sebagaimana mobilitas data saja tidak mungkin menjangkau seluruh persoalan layanan di ranah praktis. Kriteria umum yang dapat disarankan adalah sistem hibrid dengan menggabungkan mobilitas fisik secara arsitektural termasuk kombinasi antara rumah sakit 
stasioner dan mobil, dan aksesibilitas data di sisi teknologi informasi. Perkembangan digitalisasi terbaru menunjukkan bahwa sebagai sebuah sistem, rumah sakit generasi baru ini dapat dikembangkan dengan teknologi komputasi awan untuk mendukung rumah sakit kembaran digital (digital twin hospital) (Marr, 2017).

\section{Gagasan desain rumah sakit mobil}

Kondisi kedaruratan medis yang direspon secara mobil berkembang seiring dengan kemudahan transportasi di satu sisi dan kejadian bencana yang tersebar di sisi lain. Pada bagian ini kajian terhadap desain dilakukan untuk mengidentifikasi gagasan desain yang telah berkembang di literatur. Proyek desain yang dikaji disajikan dalam Tabel 1 dan dianalisis secara interpretatif untuk diungkap gagasan utamanya dalam rangka mengembangkan kriteria desain.

Tabel 1. Desain rumah sakit mobil

\begin{tabular}{|c|c|c|}
\hline Desain & Rujukan & Gagasan Utama \\
\hline Adapta & $\begin{array}{l}\text { (Harrouk, 2020, } \\
\text { https://www.50superreal.com/adapta) }\end{array}$ & $\begin{array}{l}\text { protokol penyusun modul arsitektural yang } \\
\text { disesuaikan dengan kebutuhan dan konteks, } \\
\text { masih bersifat konseptual }\end{array}$ \\
\hline CAMP-15 & $\begin{array}{l}\text { (Harrouk, 2020; } \\
\text { http://www.infektural.com) }\end{array}$ & $\begin{array}{l}\text { modul buatan yang dapat diinstalasi } \\
\text { sementara di lokasi secara fleksibel untuk } \\
\text { karantina pasien }\end{array}$ \\
\hline $\begin{array}{l}\text { CNC-Medical Emergency } \\
\text { Module oleh Kotko }\end{array}$ & (Harrouk, 2020) & $\begin{array}{l}\text { modul buatan dengan rangka dan kayu lapis } \\
\text { yang dapat dikonfigurasi dan diinstalasi } \\
\text { dengan cepat }\end{array}$ \\
\hline $\begin{array}{l}\text { Connected Units for } \\
\text { Respiratory Ailments } \\
\text { (CURA) oleh Ar. Carlo } \\
\text { Ratti }\end{array}$ & $\begin{array}{l}\text { (CURA, 2020; Harrouk, 2020; } \\
\text { Ravenscroft, 2020a) }\end{array}$ & $\begin{array}{l}\text { modul kontainer yang dirancang dengan } \\
\text { adaptabilitas tinggi dengan konfigurasi yang } \\
\text { fleksibel }\end{array}$ \\
\hline $\begin{array}{l}\text { Field Rescue Center oleh } \\
\text { HAHA Architects Group }\end{array}$ & $\begin{array}{l}\text { (Harrouk, 2020; http://hahagroup.pl/Field- } \\
\text { Rescue-Center.php) }\end{array}$ & $\begin{array}{l}\text { modul kontainer yang dimodifikasi, digabung, } \\
\text { dan diinstalasi dengan sistem hidrolik menjadi } \\
\text { fasilitas terpadu }\end{array}$ \\
\hline $\begin{array}{l}\text { Folding Emergency } \\
\text { Shelter oleh Ar. Gonzalo } \\
\text { Guzman }\end{array}$ & (Harrouk, 2020) & $\begin{array}{l}\text { modul buatan sederhana yang dapat dilipat } \\
\text { dan dipasang dengan cepat }\end{array}$ \\
\hline $\begin{array}{l}\text { Hord Coplan Macht + } \\
\text { Spevco }\end{array}$ & (Cilento, 2010) & $\begin{array}{l}\text { modul kontainer yang diangkut dengan trailer } \\
\text { dan dapat menjadi sistem mandiri yang } \\
\text { lengkap }\end{array}$ \\
\hline Jupe & $\begin{array}{l}\text { (Baldwin, 2020; Harrouk, 2020; Gibson, } \\
\text { 2020) }\end{array}$ & modul tenda sebagai ekstensi rawat inap \\
\hline Kaksh & (Harrouk, 2020; Agx Architects, t.t.) & $\begin{array}{l}\text { modul buatan khusus yang dapat dibangun } \\
\text { dan diinstalasi di lapangan cepat }\end{array}$ \\
\hline Kukil Han & (Minner, 2011) & $\begin{array}{l}\text { modul kontainer yang dimodifikasi dan } \\
\text { dikonfigurasi }\end{array}$ \\
\hline MMW & (Harrouk, 2020, Mmw (t.t.) & $\begin{array}{l}\text { modul khusus digabung, dikombinasikan, dan } \\
\text { dihubungkan dengan material selubung } \\
\text { khusus }\end{array}$ \\
\hline $\begin{array}{l}\text { QurE, Circular Negative } \\
\text { Pressure Quarantine Unit }\end{array}$ & $\begin{array}{l}\text { (Harrouk, 2020; } \\
\text { https://www.bioarch.com.tw) }\end{array}$ & $\begin{array}{l}\text { bangunan semi permanen yang sebagian besar } \\
\text { modular untuk kedaruratan }\end{array}$ \\
\hline $\begin{array}{l}\text { VHL.Architecture dan Da } \\
\text { Nang Architecture } \\
\text { University }\end{array}$ & (Harrouk, 2020) & $\begin{array}{l}\text { modifikasi kontainer menjadi modul rawat } \\
\text { inap }\end{array}$ \\
\hline $\begin{array}{l}\text { Weston Williamson + } \\
\text { Partners }\end{array}$ & (Harrouk, 2020; Ravenscroft, 2020b & $\begin{array}{l}\text { modul khusus yang diangkut dengan kapal } \\
\text { dan difungsikan sebagai rumah sakit terapung }\end{array}$ \\
\hline
\end{tabular}

Tabel 1 menunjukkan bahwa pengembangan konsep desain arsitektural semuanya menggunakan pendekatan modular namun dengan perlakuan yang berbeda-beda dan materi yang berbeda pula. Desain CURA misalnya diklaim telah diimplementasikan di banyak lokasi 
dikembangkan dengan modul yang beragam konfigurasi dan dilengkapi teknologi selubung penghubung antar modul menggunakan material yang dapat digelembungkan. Sistem ini memenuhi kriteria Airborne Infection Isolation Rooms (AIIR) (CURA, 2020). Karya Kukil Han menggunakan strategi yang berbeda yaitu kontainer yang didesain agar dapat "dibuka" dan "dilipat" dan benar mobil karena kontainer yang dipakai dapat diangkut dengan helikopter ke kawasan bencana (Minner, 2011). Karya Hord Coplan Macht + Spevco mengembangkan inovasi yang berbeda yaitu rumah sakit 48 tempat tidur menggunakan 58 trailer yang sepenuhnya operasional dan mobil. Trailer tersebut mendukung setiap aspek rumah sakit: dari ruang bedah, apotek, laboratorium, hingga toko suvenir. Dengan model ini maka sistem layanan kesehatan akan berubah karena tidak lagi hanya mengandalkan pasien yang hadir ke rumah sakit tetapi rumah sakit yang akan mendatangi pasien-pasien yang membutuhkan (Cilento, 2010).

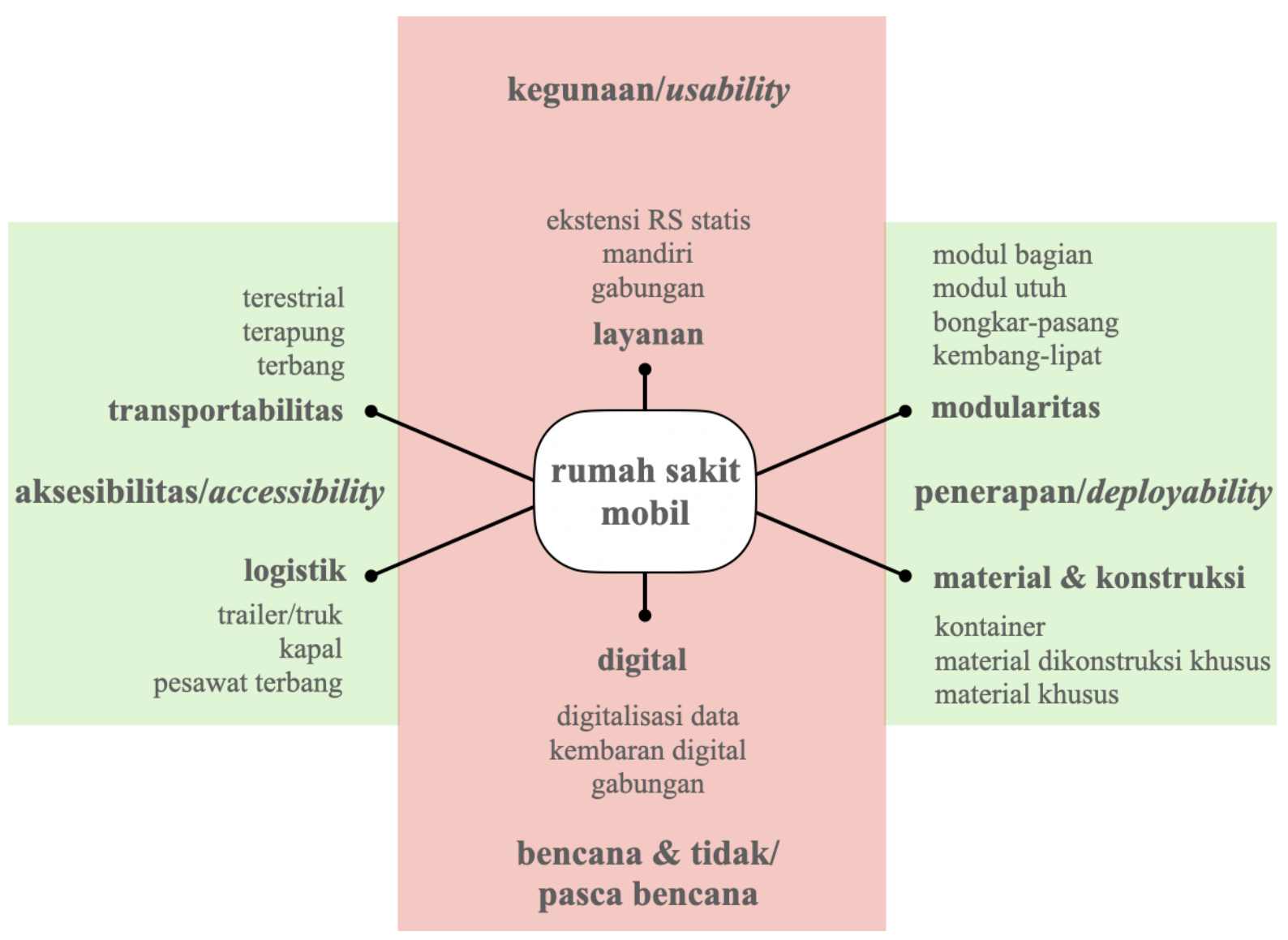

Gambar 2. Diagram kriteria desain rumah sakit mobil

(sumber: analisis)

Gambar 2 menunjukkan analisis terhadap rancangan yang disajikan pada Tabel 1 dalam rangka menyusun kriteria desain yang signifikan dan relevan. Secara garis besar, kriteriakriteria yang terlah diindikasikan oleh Bakowski (2016), Chen dkk. (2020), dan Khalifa dkk. (2013) dipakai sebagai kerangka kerja awal dan diperkaya dengan temuan desain dari Tabel 1. Kriteria yang ditemukan dari penelusuran literatur dan desain dapat dikembangkan menjadi enam kriteria. Kriteria layanan merujuk pada relasinya dengan rumah sakit statis yaitu sebagai ekstensi, mandiri, atau merupakan gabungan (dapat sebagai ekstensi atau mandiri). Kriteria logistik merujuk pada kemudahan untuk pengangkutan memakai truk, kapal, kapal terbang, atau dapat diangkut semua moda. Logistik ini terkait dengan transportabilitasnya yaitu rumah sakit darat (terestrial), terapung, atau terbang. Kriteria modularitas merujuk pada bentuk modul 
yang dapat berupa bagian-bagian (parts), utuh, bongkar-pasang, atau kembang-lipat dalam rangka memudahkan keterterapan atau deployability. Modularitas ini sangat terkait dengan material dan konstruksinya pula. Kriteria terakhir terkait digitalisasi yang dapat berupa infrastruktur data (misalnya rekam medis), hingga sistem kompleks kembaran digital rumah sakit secara utuh.

\section{Pembahasan}

Telaah literatur dan desain di atas menunjukkan bahwa ide pengembangan rumah sakit mobil telah berkembang luas. Walaupun sebagian dari gagasan di atas masih berupa konsep, namun implementasi rumah sakit mobil telah banyak dilaporkan (Harrouk, 2020). Kebutuhan rumah sakit mobil ini sebenarnya didasari oleh alasan yang sangat sederhana yaitu fasilitas kesehatan dibutuhkan di mana-mana, tidak dibatasi oleh ruang dan waktu, sementara layanan kesehatan yang ada didasarkan pada fasilitas kesehatan yang statis (stationary health facility) terbatas layanan baik dari sisi ruang dan waktunya. Laporan dari beragam kasus penanganan bencana mengkonfirmasi hal tersebut. Penelitian Acar \& Kaya (2019) terhadap bencana gempa bumi di Turki menunjukkan bahwa rumah sakit mobil dapat meningkatkan signifikan layanan kesehatan asalkan anggaran yang cukup dialokasikan untuk jenis fasilitas tersebut.

Studi kasus mereka juga memberikan wawasan manajerial yang penting yaitu perlunya upaya meminimalkan waktu respons total dengan mempertimbangkan mobilitas dari satu lokasi ke lokasi bencana lain (Acar \& Kaya, 2019). Dari China dilaporkan pula penggunaan rumah sakit darurat oleh Cheng dkk. (2015). Struktur rumah sakit khusus untuk bedah ini terdiri dari modul kontainer yang diangkut dengan kendaraan dilengkapi dengan kendaraan untuk pemeriksaan Rontgen, tes laboratorium, dan kendaraan logistik. Rumah sakit dapat beroperasi dengan berintikan pada kendaraan yang dikombinasi dengan kabin dan tenda tiup serta kemampuan teknologi informasi. Rumah sakit bedah keliling ini dapat dirakit untuk mengadopsi persyaratan fungsional dan kapasitas perawatan yang berbeda sesuai dengan keadaan yang berbeda. Penggunaan fasilitas yang mirip juga dilaporkan untuk bencana Katrina oleh Blackwell dan Bosse (2007). Penggunaan di arena terpencil juga pernah dilaporkan walau masih dalam tahap kompetisi desain (Building Trust International, 2014).

Pada konteks Indonesia, praktik layanan kesehatan yang mobil telah dilaksanakan utamanya Batalyon Kesehatan TNI (https://tniad.mil.id/tni-kembali-kirim-batalyon-kesehatanke-lombok). Namun demikian, berbasis focus group discussion yang telah dilakukan, diindikasikan masih banyak persoalan teknis yang terkait dengan fleksibilitas pengoperasian dan pengangkutan terutama kemampuannya untuk diangkat, diangkut dan dioperasikan di dek atau di lambung kapal atau Hercules C-130 ke lokasi yang dituju. Dibandingkan dengan gagasan desain pada Tabel 1, masih diperlukan solusi desain yang mampu memperkuat aspek modularitas dan mobilitas.

Dalam diskusi ditekankan bahwa kriteria modularitas, terutama pada kemampuan bongkar-pasang dengan cepat dan ringkas, menjadi penting sebagaimana disarankan Bakowski (2016). Merujuk pada RSKI Pulau Galang yang dibangun modular dengan kontainer memang signifikan mempercepat proses pembangunan. Namun dari sisi arsitektur rumah sakit ini sebenarnya tidak berbeda dengan rumah sakit pada umumnya karena dalam desain tidak dapat "dibongkar" kembali. Kontainer dipakai sebagai material dan struktur untuk membentuk ruang dengan penyesuaian dinding, perlobangan, penggabungan, dan penumpangtindihan. Dengan demikian, solusi arsitektural ini memang modular namun tidak dirancang untuk bongkar pasang sehingga aspek mobilitasnya menjadi nihil.

Merefleksi kasus RSKI ini, artikel ini mengusulkan perlunya aspek yang baru yaitu usability yang merujuk pada penggunaan di masa tidak bencana. Isu penggunaan di masa tidak bencana ini mengemuka karena adanya potensi kegagalan RSKI Pulau Galang ketika kepentingan karantina usai. Dengan demikian, artikel ini juga menegaskan bahwa kriteria 
sukses rumah sakit mobil adalah pada: (a) aksesibilitas fasilitas yang dapat dicapai logistik dan transportabilitasnya, (b) deploability yang dicapai dengan modularitas, material dan konstruksinya, serta (c) usability pasca bencana yang dirancang secara integratif baik dalam konteks layanan maupun digitalnya. Rumah sakit mobil ini dapat didukung dengan infrastruktur digital agar ke depan ide infrastruktur rumah sakit awan (cloud hospital) dan rumah sakit kembaran digital dapat terwujud sebagai bagian integral penanganan bencana dan pandemi.

Dilihat dari kriteri-kriteria yang dirumuskan dalam artikel ini tampak bahwa Indonesia belum mengadopsi konsep mobilitas yang komprehensif di tengah ancaman bencana dan pandemi. Sudah saatnya instrumen kebijakan yang masih dominan didesain sebagai layanan kesehatan berbasis rumah sakit statis dan permanen (stationary hospital) perlu diadaptasikan dengan kehadiran teknologi mobil dan digital. Dalam jangka panjang model ini dapat mendisrupsi model layanan kesehatan berbasis rumah sakit permanen. Hal ini karena terjadi perubahan prinsip desain yang dikembangkan dari sisi relasi antara rumah sakit dan pasien. Desain rumah sakit permanen yang menjadi standar layanan kesehatan adalah sistem berbasis people come to hospital. Desain rumah sakit mobil mengubahnya menjadi berbasis hospital comes to people sebagaimana diindikasikan oleh Khanna dan Narula (2016).

Tentu saja dalam pengembangan ini aspek-aspek non arsitektural seperti bagaimana adopsi dan adaptasi oleh profesional medis dan paramedis perlu menjadi perhatian sebagaimana diindikasikan oleh Wu dkk. (2011) serta pengembangan penjaminan mutu layanan (Sunder dkk., 2020). Kedua aspek ini di luar cakupan kajian ini dan menjadi tantangan bagi pengembangan RSM ke depan.

\section{SIMPULAN DAN SARAN}

Berbasis kajian literatur dan desain, rumah sakit mobil mengisi celah yang ditimbulkan oleh ketersediaan rumah sakit statis atau permanen dengan kondisi kebencanaan, pandemi, dan geografi Indonesia. Artikel ini mengusulkan enam kerangka kriteria desain untuk rumah sakit mobil yaitu (a) layanan merujuk pada relasinya dengan rumah sakit statis, (b) logistik merujuk pada kemudahan untuk pengangkutan, (c) transportabilitas, (d) modularitas merujuk pada bentuk modul dalam rangka deployability, (e material dan konstruksi, dan (f) digitalisasi. Sebagai kontenstualisasi dengan Indonesia, artikel ini mengusulkan aspek baru yaitu kegunaan (usability) yang merujuk pada penggunaan pasca bencana yang harus dirancang secara integratif sejak awal. Keenam kriteria di atas dapat dikerangkakan menjadi tiga pendekatan desain utama yaitu (a) aksesibilitas fasilitas yang dikembangkan dari desain logistik dan transportabilitasnya, (b) deploability yang dirancang melalui modularitas, material, dan konstruksinya, serta (c) usability yang dirancang secara integratif baik dalam konteks integrasinya dengan rumah sakit statis atau permanen maupun layanan dan karakteristik infrastruktur digitalnya di masa bencana maupun tidak atau pasca bencana.

Artikel ini menyarankan agar Indonesia segera menyusun kebijakan komprehensif terkait dengan rumah sakit mobil ini agar layanan kesehatan dapat berkembang lebih lincah dalam merespons bencana maupun pandemi.

\section{UCAPAN TERIMA KASIH}

Artikel ini merupakan luaran dari hibah penelitian yang didanai oleh Universitas Islam Indonesia dan Rumah Sakit JIH Yogyakarta (Nomor: 10 /Dir/DPPM/70/Pen.Unggulan.JIH Research Grant/2020). Penulis memberikan penghargaan setinggi-tingginya dan doa terbaik kepada Setyawan Wahyu Pratomo,S.T., M.T. yang turut berperan sebagai anggota tim peneliti akan tetapi wafat ketika proses publikasi ini dilakukan.

\section{DAFTAR RUJUKAN}


Acar, M., \& Kaya, O. 2019. A healthcare network design model with mobile hospitals for disaster preparedness: A case study for Istanbul earthquake. Transportation Research Part E: Logistics and Transportation Review, 130, 273-292. doi:10.1016/j.tre.2019.09.007.

Agx Architects, tanpa tahun. Kaksh. https://www.agxarchitects.com/copy-of-urban-generator3 diakses 8 Juni 2021.

Bakowski, J. 2016. A mobile hospital - Its advantages and functional limitations. International Journal of Safety and Security Engineering, 6(4), 746-754. doi:10.2495/SAFE-V6-N4746-754.

Baldwin, E. 2020. 'JUPE Health Designs Mobile Units to Address Hospital Bed Shortage from COVID-1', ArchDaily, 28 Maret 2020 https:/www.archdaily.com/936378/jupehealth-designs-mobile-units-to-address-hospital-bed-shortage-from-covid19?ad_source=search\&ad_medium=search_result_all.

Blackwell, T., \& Bosse, M. 2007. Use of an Innovative Design Mobile Hospital in the Medical Response to Hurricane Katrina. Annals of Emergency Medicine, 49(5), hlm. 580-588. doi: 10.1016/j.annemergmed.2006.06.03.

Blessing, L. T. M., \& Chakrabarti. A. 2009. DRM, a Design Research Methodology. London: Springer-Verlag, doi: 10.1007/978-1-84882-587-1.

Building Trust International (2014) Prefab truck and shipping container win healthcare facility design competition. https://newatlas.com/building-trust-international-moved-tocare/31738/ diakses 8 Juni 2021.

Chen, X., Lu, L., Shi, J., Zhang, X., Fan, H., Fan, B., ... Hou, S. 2020. Application and Prospect of Mobile Hospital in Disaster Response. Disaster Medicine and Public Health Preparedness, May, hlm. 1-7, doi: 10.1017/dmp.2020.113.

Cheng, B., Shi, R., Du, D., Hu, P., Feng, J., Huang, G., Yang, R. 2015. Mobile emergency (surgical) hospital: Development and application in medical relief of "4.20" Lushan earthquake in Sichuan Province, China. Chinese Journal of Traumatology - English Edition. doi: 10.1016/j.cjtee.2014.07.004.

Cilento, K. 2010 'Mobile Hospital / Hord Coplan Macht + Spevco', ArchDaily. https://www.archdaily.com/54890/mobile-hospital-hord-coplan-macht-spevco.

CURA 2020. CURA Connected Units for Respiratory Ailments https://curapods.org diakses 8 June 2021.

Djalante, R., Lassa, J., Setiamarga, D., Sudjatma, A., Indrawan, M., Haryanto, B. Mahfud, C., Sinapoy, M.S., Djalante, S., Rafliana, I., Gunawan, L.A., Surtiari, G.A.K., Warsilah, H. 2020 'Review and analysis of current responses to COVID-19 in Indonesia: Period of January to March 2020', Progress in Disaster Science, 6, hlm. 100091. doi: 10.1016/j.pdisas.2020.100091.

Dolev, E. 2020. History of Military Field Hospitals. Field Hospitals, hlm. 1-11. doi: 10.1017/9781316493489.001.

Ferrari, R. 2015 'Writing narrative literature reviews', The European Medical Writers Association, 24(4), hlm. 230-235. doi: 10.1179/2047480615Z.000000000329.

Gibson, E. 2020. 'Jupe designs flat-pack intensive care unit to bolster hospitals impacted by coronavirus', Dezeen https://www.dezeen.com/2020/03/27/jupe-health-flat-packedcoronavirus-care-units/.

Harrouk, C. 2020. 'Alternative Healthcare Facilities: Architects Mobilize their Creativity in Fight against COVID-19', ArchDaily https://www.archdaily.com/937840/alternativehealthcare-facilities-architects-mobilize-their-creativity-in-fight-against-covid19 ?ad_source $=$ search \&ad_medium $=$ search_result_all.

http://hahagroup.pl/Field-Rescue-Center.php diakses 8 Juni 2021.

http://puskes-tni.mil.id/admin/peraturan/peraturan_9.pdf diakses 4 Juni 2021. 
http://www.infektural.com diakses 8 Juni 2021.

https://archello.com/project/emergency-modular-hospital diakses 8 Juni 2021.

https://hospitainer.com diakses 8 Juni 2021.

https://khomesteelstructure.en.made-in-china.com/product/MBQJutilsbrk/China-

Prefabricated-Modular-Container-Mobile-Clinics.html diakses 8 Juni 2021.

https://newatlas.com/building-trust-international-moved-to-care/31738 diakses 8 April 2020.

https://nusantara.rmol.id/read/2021/02/09/474280/tangani-covid-19-ksad-perintahkan-

tambah-kapasitas-rs-lapangan diakses 8 Juni 2021.

https://superkontainer.com/jual-klinik-container diakses 8 April 2020.

https://tniad.mil.id/tni-kembali-kirim-batalyon-kesehatan-ke-lombok diakses 8 Juni 2021.

https://www.50superreal.com/adapta diakses 8 Juni 2021.

https://www.agxarchitects.com/copy-of-urban-generator-3 diakses 8 Juni 2021.

https://www.archdaily.com diakses 8 Juni 2021.

https://www.bioarch.com.tw diakses 8 Juni 2021.

https://www.britannica.com/science/mobile-army-surgical-hospital diakses 31 Mei 2020.

https://www.dezeen.com diakses 8 Juni 2021.

https://www.pikiran-rakyat.com/nasional/pr-011521435/para-ahli-nilai-pemerintah-salahkaprah-bangun-rski-covid-19-di-pulau-galang diakses 8 Juni 2021.

Hugo, M., Smout, M., \& Bannister, J. 2002. A comparison in hospitalization rates between a community-based mobile emergency service and a hospital-based emergency service. Australian and New Zealand Journal of Psychiatry, 36(4), hlm. 504-508. doi: 10.1046/j.1440-1614.2002.01042.x.

Jan, R. 1996. Rufaida Al-Asalmiya, the First Muslim Nurse. The Journal of Nursing Scholarship, 28(3), hlm. 267-268. doi: 10.1111/j.1547-5069.1996.tb00362.x.

Khalifa, I., Abd Al-glil, H., \& M. Abbassy, M. 2013. Mobile Hospitalization. International Journal of Computer Applications, 80(13), hlm. 18-23. doi: 10.5120/13921-1822.

Khanna, A. B. \& Narula, S. A. 2016. 'Mobile health units: Mobilizing healthcare to reach unreachable', International Journal of Healthcare Management. Taylor \& Francis, 9(1), hlm. 58-66. doi: 10.1080/20479700.2015.1101915.

King, B., \& Jatoi, I. 2005. The mobile army surgical hospital (MASH): A military and surgical legacy. Journal of the National Medical Association, 97(5), hlm. 648-656.

Marr, B. 2017. What Is Digital Twin Technology - And Why Is It So Important?, https://www.forbes.com/sites/bernardmarr/2017/03/06/what-is-digital-twintechnology-and-why-is-it-so-important/\#3ffb4ca92e2a diakses 16 Desember 2019.

Minner, K. 2011. 'Mobile Hospital / Kukil Han', ArchDaily. https://www.archdaily.com/153047/mobile-hospital-kukil-han.

Mmw (tanpa tahun) Mmw. https://www.mmw.no/emergencymodularhospital diakses 8 June 2021.

Ravenscroft, T. 2020a 'Carlo Ratti Associati designs shipping-container intensive care units for coronavirus treatment', Dezeen https://www.dezeen.com/2020/03/24/shippingcontainer-intensive-care-units-coronavirus-covid-19-carlo-ratti.

Revenscroft, T. 2020b 'Weston Williamson + Partners proposes turning container ships into floating coronavirus hospitals', Dezeen https:/www.dezeen.com/2020/04/09/westonwilliamson-partners-proposes-turning-container-ships-into-floating-coronavirushospitals.

Sunder M, V., Mahalingam, S., \& Krishna M, S. N. 2020. Improving patients' satisfaction in a mobile hospital using Lean Six Sigma-a design-thinking intervention. Production Planning and Control, 31(6), hlm. 512-526 doi: 10.1080/09537287.2019.1654628.

Tahiliani ND, Kumar P, Mittal VN. Initial experiences in a mobile hospital. J Indian Med Assoc. 1973;60(2) hlm. 66-68. 
Undang-Undang No 4 tahun 2009 Tentang Rumah Sakit.

Widayatun \& Fatoni, Z. 2013. 'Permasalahan Kesehatan dalam Kondisi Bencana:Peran Petugas Kesehatan dan Partisipasi Masyarakat (Health Problems in a Disaster Situation: the Role of Health Personnels and Community Participation)', Jurnal Kependudukan Indonesia, 8(1), hlm. 37-52.

Wu, I.-L., Li, J.-Y., \& Fu, C.-Y. 2011. The adoption of mobile healthcare by hospital's professionals: An integrative perspective. Decision Support Systems, 51(3), 587-596 doi: 10.1016/j.dss.2011.03.003. 